\title{
Supply Chain Networks for Perishable and Essential Commodities: Design and Vulnerabilities
}

\author{
Aruna Apte \\ Graduate School of Business and Public Policy \\ Naval Postgraduate School \\ auapte@nps.edu
}

\begin{abstract}
This paper presents the results of our case-based research into the causes and remedies of fresh produce supply chain disruptions resulting from contamination. The research was motivated by the incident of E-coli outbreak in packaged spinach in the US. We base our analysis on information gathered from published literature and data collection in the region from personnel involved in Agriculture. Our research is aimed at addressing the following research questions: What key factors contribute to the vulnerability to disruption from contamination and what are the interrelationships between these contributing factors? What managerial actions may be taken to minimize the fresh produce supply chain's vulnerability to disruption? In this research we develop a conceptual framework consisting of the contributing factors: product type, topological structure, exposure to contamination, product traceability, and communication. The practice related contributions of this research are managerial insight and recommended actions derived from the proposed conceptual framework.
\end{abstract}

Keywords: supply chain network, disruption, contamination, vulnerability, perishable, essential

\section{INTRODUCTION}

The fresh produce supply chain in the US is highly industrialized and is characterized by its length and complexity. Pollan's (2006) research emphasizes how vulnerable the industry is to contamination - both accidental and deliberate. Driven by the economies of scale, an industrialized food supply chain can be impressively efficient, but its complexity also makes it difficult to map this supply chain, and understand and analyze it so as to rectify its vulnerabilities.

The intrinsic characteristics of food products - especially their perishability - and the necessity to maintain a high level of consumer confidence in product safety make management of supply chains for food products particularly challenging. Additionally, the fresh produce supply chains are accompanied by economic tradeoffs between the product availability and food supply safety, which compound the difficulty of managing supply chain network (SCN) disruptions. This is mainly because the perishability of fresh produce makes it necessary that the industry distribute the product quickly (depending on the particular type of fruit or vegetable) irrespective of the existing market prices (Folinas et al. 2006). Recent history shows that the fear of contamination of fresh produce by bacteria or chemicals and the resulting disruption of their supply chains have increased consumers' sensitivity to and awareness of the quality of fresh produce. In short, managing any food supply chain is inherently difficult (Roth et al. 2008) but the fresh produce supply chain (FPSC) brings its own set of challenges. The need for rapid distribution also causes financial strain, since, as such, most agribusinesses in the US operate on narrow profit margins.

"A disruption is defined as a major breakdown in production or distribution nodes that impacts other nodes in the supply chain" (Handfield et al. 2008). We recognize that many factors can cause supply chain disruptions. Some of these factors have been studied in the current literature on supply chain risks (Dani 2008, Mullal 2008, Khan et al. 2008, Wagner and Bode 2008, Hendricks and Singhal 2009) 
wherein the focus is on the "human, environmental and property impacts" of accidental events. However, in this research we are mainly concerned about the vulnerability of a supply chain to disruptions, where vulnerability is viewed in the context of "system mission and survivability of the system" (Asbjornslett 2008).

As defined by Peck (2005), vulnerability is "the sense that something - a product, process or organization, etc. - is vulnerable; likely to be lost or damaged". Furthermore, as viewed by Svensson (2000), the vulnerability of supply chain is the "existence of random disturbances that lead to deviation in the supply chain of components and materials from normal, expected or planned schedule or activities, all of which have negative effects or consequences". Given that the instances of supply chain disruptions arising from contaminations of fresh produce are on the rise, and that there exists a paucity of research into the causes and management of these disruptions, the research presented in this paper focuses on the vulnerability to disruption of the fresh produce supply chain arising from contaminations.

Peck (2005) uses the above definition of vulnerability to discuss the factors that drive SCN vulnerability in a case study of the Aerospace industry in the United Kingdom. The article explains why this particular SCN is vulnerable, but does not suggest how it can be managed and what specific actions the management should take to minimize the SCN vulnerability. Hence, our research is aimed at addressing the following research questions: What key factors contribute to the vulnerability to disruption from contamination and what are the interrelationships between these contributing factors? What managerial actions may be taken to minimize the FP-SC's vulnerability to disruption? As an integral part of this research, we also plan to conduct a case study of FP-SC disruption arising from contamination so that concepts we develop in the research can be applied to a reallife situation and lessons can be learned from the insights generated in the case study.

The next section briefly reviews relevant literature. This is followed by a discussion of the research methodology in the third section. The fourth section presents five factors contributing to the FP-SC disruption from contamination and ends with a proposed framework based on these contributing factors. An application of the proposed framework and concepts is presented in the fifth section. In this section we study the 2006 Salinas Valley spinach con- tamination case, in which 200 people from 26 states fell sick after consuming spinach contaminated with E. coli. The main conclusion of the study, a discussion of the theory and practice-oriented contributions of this research, and the suggestions for future research on the topic are presented in the final sections of the paper.

\section{LITERATURE REVIEW}

"It seems that many companies are not adequately prepared for assessing and addressing supply chain disruptions", (Hendricks and Singhal 2009). One of the reasons, why that is so, is because the companies do not have a good understanding of the causes and consequences of disruption. In case of FP-SC other reasons could be the research questions raised in the previous section. In this section we review the literature that is related to these research questions- factors contributing to the vulnerability of fresh produce supply chain network, and how the FP-SC can be managed to minimize vulnerability to disruption.

The research work by Fisher's (1997) and Fine (1998) provide some fundamental concepts useful in understanding the characteristics of the fresh produce supply chains. Specifically, Fisher (1997) sheds light on how product type affects the structure and classification of supply chains, while Fine (1998) presents a model concerning perishable and essential commodities.

Two researchers suggest that future demand for "customer-convenient" food items will lead to dynamically changing SCNs (Harland et al.1999) and those SCNs will differ substantially based on the product type being handled in the supply chain (Lamming et al.2000). Additionally, this demand for customized new products will create a continuum for dynamically transforming essential/basic products into non-essential/value-added products and that the degree of product differentiation will influence how SCNs should be managed. Choosing the right supply chain structure is based on the nature of the product (Fisher 1997). The dichotomy of innovative versus functional product types is extended by Lamming et al. (2000) to include the uniqueness of the product. An important conclusion that can be drawn from the above set of literature (Fisher 1997, Lamming et al. 1999, and Harland et al. 2004) is that SCN design and its vulnerability critically depend on the product type. 
Various alternate SCN structures are common in current practice (Chopra and Meindl 2004). These include knowledge-sharing-based (Dyer and Nobeoka 2000), structure-based (Harland and Knight 2001), strategy-based (Harland et al. 1999), and contextual factor-based (Harland et al. 2004) supply chains. The topological structure and the existence of hubs in a SCN are factors of importance to managing systemic failures in utility industries (Watts 1999, Barabassi 2003, Lewis 2006). This second set of literature suggests that SCN design and its topological structure are factors that should be studied for their impact on the vulnerability to disruption in FP-SC.

Success of a SCN depends on the exchange and processing of information between supplier and buyer. Hence, communication, a proactive intervention, plays important role in managing SCN (Harland et al. 2004). Managing communication is also useful for managing uncertainties in supply and demand. Within the food industry, communication is even more critical since consumers cannot directly access food safety risk information (Yee et al. 2005). Consumers' perception of food safety, to some extent, is shaped by their trust in the SCN. Wilson and Clarke (1998) emphasize that the agricultural industry in particular must collect, store, and offer safety-related information regarding all products to develop consumer trust. Yee et al. (2005) also indicate that, "trust can be destroyed when information provided is perceived to be amplified, biased and not factual or proven wrong." Miscommunication leads to lack of consumer confidence in the product. This loss of consumer confidence can lead to uncertainty and fluctuations in the product demand.

Food safety is one of the most important aspects of any food SCN (Roth et al. 2008). Contamination can lead to uncertainty in supply and demand which translates to disruption in distribution. In other words, exposure to contamination can play an important role in FP-SC's vulnerability to disruption.
In order to minimize exposure to contaminations, Manning et al. (2006) assert that effective food safety measures must be present in the primary production and that the SCN must maintain a hygienic environment throughout the distribution system.

As Wilson and Clarke (1998) and Roth et al. (2008) argue, safety concerns can be managed by ensuring product traceability. Wilson and Clarke (1998) define traceability as, "that information necessary to describe the production history of a food crop and any subsequent transformation or processes that the crop might be subject to on its journeys from grower to consumer's plate." Traceability can be further examined from a quantitative, logistics perspective and a qualitative, information availability perspective (Folinas et al. 2006). Such traceability can facilitate locating the source of contamination, thus managing supply side of the supply chain. But not having product traceability can add greatly to the vulnerability to disruption. The "fine-grain information transfer" needed to establish consumer trust in a company is dependent on traceability (Uzzi 1997). Roth et al. (2008) also include traceability as one of the six " $\mathrm{T}$ 's" in discussing the 2007 food supply chain recalls from China. The ability to track the flow of a product (Golan et al. 2004) and the exact path in the SCN for that product depends on the product type (Maloni and Brown 2006).

\section{RESEARCH METHODOLOGY}

We now describe our methodology in identifying the contributing factors. Derived from multiple approaches established in the field, the methodology is primarily based on Meredith (1993) and consists of an iterative process of literature review (as described in the previous section) followed by a case study to build a conceptual model. However, instead of employing numerous case studies, this research carries out an in-depth study of a single case while examining it from different perspectives. 
Figure 1: Modeling Process and Research Design



A conceptual model requires balancing of the "coarse-grained" approach (Morgan et al. 2005) focusing on current practices as well as the "finegrained" approach (Morgan et al. 2005) for identifying important contributing factors. We bridged these conflicting requirements by iteratively synthesizing literature and practice-based insights to develop a conceptual framework that identified the contributing factors and managerial levers for minimizing the FP-SC vulnerabilities. Figure 1 illustrates our modeling process and research design.

\subsection{Case Study Method}

Case studies/empirical research are critical for formulating conceptual models and frameworks (Meredith 1993, Yin 2003), which can then be expanded to theory by bolstering descriptive models into explanatory frameworks through further study (Meredith 1993). In addition, this research methodology parallels the methodology proposed and adopted by Morgan et al. (2005) who "draw insights from field research and extant literature to develop a model, identifying the key components and how they are linked together".

Yin (2003) indicates that when relevant case studies are inaccessible, two evidence sources can be successfully substituted: (1) direct event observation; and (2) interviews of persons involved in the events. In addition, Van Donk and Van Dam (1996) validated the use of only one case study that is typical for a given industry, which can provide more in-depth analysis of industry structure, practices and deficiencies than multiple case studies. This research employs a single case study, direct observation of subsequent events, and interviews with producers (growers), processors, distributors, quality-assurance teams, and the regulatory board of the fresh produce industry operating in the immediate geographic region (Westbrook 1995).

\subsection{Data Collection}

Data collection was motivated by our intention to identify factors contributing to the vulnerability to disruption of the FP-SC due to contamination (Peck 2005, Morgan et al. 2005). The data collection process also validated our understanding of these contributing factors along with their interrelationships and their roles as management levers in minimizing the disruption.

Data collection included various instruments such as presentation, discussion, one-on-one interview, and field trips. This was facilitated by AgKnowledge seminars (a nonprofit educational organization in Monterey County, California). Table 1 in the Appendix lists interview profiles and fieldwork sites while indicating sector, interviewee role in this sector, instruments (presentation, discussion, one-on-one interview, or field trip with source indicated by check-mark), geographical site (refer to Figure 2), and supported contributing factor(s) (Peck 2005, Morgan et al. 2005).

Data sources involved various sectors of the fresh produce industry in the Salinas Valley. The sources were chosen so as to understand the perspectives of 
all important players in the industry. Consequently, the subject matter experts were selected from various sectors, such as growers, processors, and distribution centers that form the major nodes of the fresh produce supply chain. Also chosen were the experts from sectors that provided resources in the supply chain such as air, water, land, fertilizer, and seeds; and from other support sectors such as research and development, food safety, technology. Based on presentations by subject matter experts, discussions during and after these presentations, specific concerns expressed by the experts during interviews, and our observation in the field trips helped us identify the factors contributing to disruption from contamination. In total, we communicated about forty experts in developing and fine tuning the proposed conceptual model.

\section{Figure 2: Case Study Geographical Sites in Monterey County}

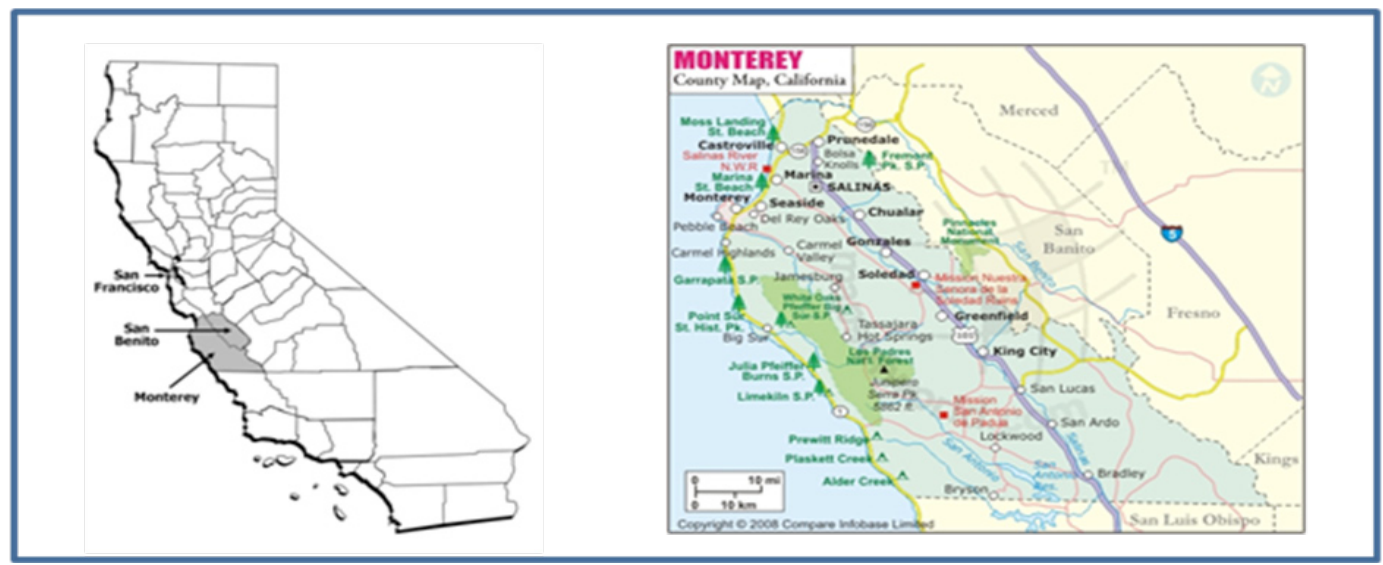

The presentations were done by representatives of the corresponding sectors and typical presentation team included one to three people. These were subject matter experts in the area. For example, a senior elected public official in the presentation on agricultural issues described the critical role played by communication during instances of disruption of FP-SC and its use as a tool to reducing the vulnerability to such disruption.

Discussions were conducted as a follow up to the presentations that involved questions and answers between the audience and the presenters. For example, after the presentation on air as a resource, the air pollution controller and some from the audience got involved in a heated discussion about the level of exposure to contamination due to air. We want to mention that discussions also took place during interviews and field trips.

One-on-one interviews with the subject matter experts provided in-depth look into the industry for the authors. For example, from produce processing sector we learned that major issues related to vulnerability to disruption from contamination are the topological structure of the up-steam supply chain, exposure to contamination at that node, and the traceability aspects of the product in-flow and out-flow. Field trips were another instrument that added insight into the fresh produce supply chain, especially in the production, processing and distribution stages. The next section delves further into the conceptual framework we developed.

\section{CONTRIBUTING FACTORS: A CONCEPTUAL FRAMEWORK}

Following the approach adopted by Peck (2005) in the analysis of vulnerability to disruption in the Aerospace industry supply chain, we investigate factors contributing to disruption in the fresh produce supply chain networks. As we identify and discuss below, the vulnerability to disruption from contamination in FP-SC is dictated by five contributing factors: product type; topological structure; exposure to contamination; product traceability; and communication. We provide below detailed characterization of each contributing factor in a separate subsection, followed by the proposed conceptual framework involving these factors in the last subsection.

\subsection{Product Type}

In the context of this research, two types of product classifications are considered: perishable vs. nonper- 
ishable and the degree of consumer-perceived essentialness of a product represented on a continuum from being considered an essential product to a nonessential product. The term essential product is based on the commonly understood definition of essential; "that which constitutes absolute essence or the fundamental nature of a thing and, therefore, must be present for the thing to exist" (Webster's 1980). Figure 3 describes the potential for disruption from contamination as being high, medium, or low based on the product's perishability and essentialness.

The terms essential, somewhat-essential and non-essential are used for convenience in discussing products and they represent points along the essentialness continuum (Smith 2000). Essential products typically include staple products that customers buy to satisfy basic needs. Examples of essential products include certain fresh produce, milk and meat (Wein 2005, Pollan 2006). Non-essential products lie at the other end of the spectrum - products not essential for normal, daily life and whose unavailability does not cause fear or anxiety among consumers, only an inconvenience. Examples of non-essential products include value-added products, such as: ready-to-eat fresh produce, ice cream, and prepared foods. Some- what-essential products fall between the prior definitions, with examples being different mixes of salad greens or milk types with different fat content.

Furthermore, these products fall under different categories based on their level of value-added and substitutability. As such, producers can cater to consumer demand for convenience - and thereby charge a premium price - by adding value to transform essential products into somewhat-essential or even nonessential products. An example of this phenomenon is a head of lettuce (an essential product) which can be transformed into cut-and-washed lettuce (a somewhat essential product) and further transformed into ready-to-eat lettuce salad-kits (a non-essential product). When consumers start to view the value-added products as necessary due to newly formed habits, the continuum can shift and the non-essential commodity take on somewhat-essential commodity characteristics, thus leading to a dynamic definition of essentialness and increased product pricing. Although this transformation adds to the managerial challenges and complexity of the SCN, for the purposes of this research, a snapshot approach of the status is taken to limit the scope of the current research to a static classification of essential products.

Figure 3: Product Type: Potential for Disruption from Contamination

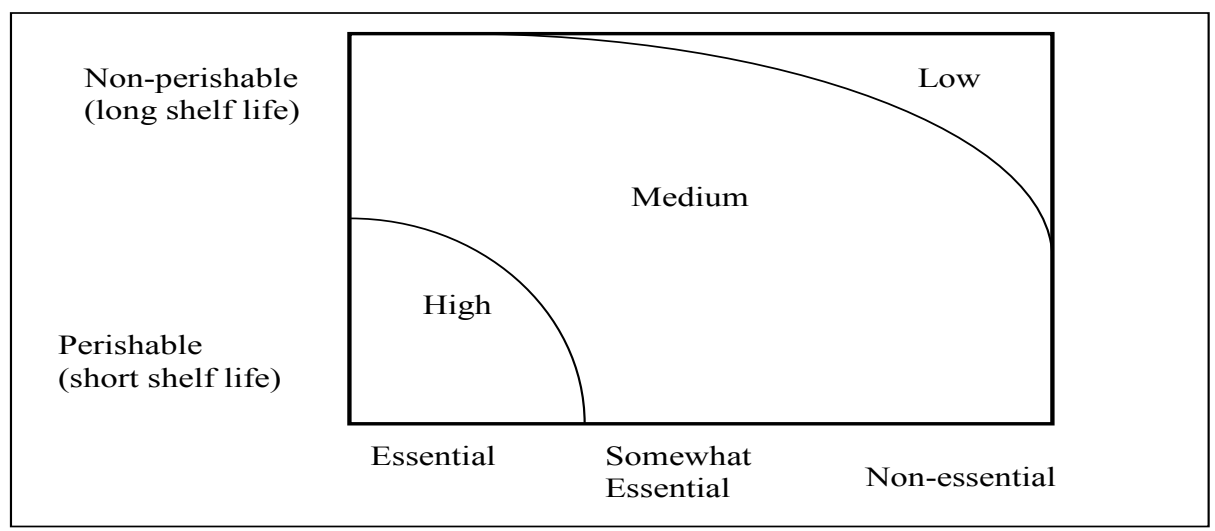

In considering perishability, supply chain disruptions of an essential product with a long shelf life can be managed with buffer stock inventory. If, in contrast, the commodity is perishable, supply chain networks become more sensitive to vulnerabilities, and as a result the managerial difficulties are compounded. Most perishable products contain organic compounds, which without the addition of preservatives or proper temperature control are prone to spoilage from harmful bacteria. Examples include tomatoes and cantaloupes which are susceptible to contamination by salmonella, and lettuce and leafy greens which are susceptible to contamination by E. coli (especially 0157:H7).

As shown in the lower left corner of Figure 3, the supply chains of products that are perishable and essential suffer from greater potential for disruption from contamination. At the diagonally opposite end in the top right corner of the figure, supply chains of 
products that are non-perishable and non-essential are less prone to disruptions from contamination.

In summary, we view product type as a factor contributing to SCN's vulnerability to disruption and propose that food products be categorized in terms of their essentialness and perishability. However, it should be kept in mind that although the choice of which product to grow or distribute is determined by the individual business; once this decision is made, the product type becomes an important yet non-controllable contributing factor.

\subsection{Topological Structure of the Supply Chain Net- work}

In its simplest form, a supply chain for perishable and essential product is similar in its structure to a manufacturing supply chain (Chopra and Meindl 2004). It is illustrated in Figure 4. Unlike traditional networks analyzed in optimization literature (Ahuja et al. 1993) which specifically deal with supply, demand, and capacity constraints, this research focuses on the topological structure of SCN.

As a starting point in understanding and analyzing the topological structure of the FP-SC it is useful to understand the nature of and relationships amongst its four constituent parties: growers, processors, distribution centers, and retailers. The growers can be classified as being large or medium or small, based on their size and market reach; the fresh produce processors as being grower-owned and independent; the distribution centers (DC) as being owned by a grower, owned by a processor, or owned by a retailer; and the retailers ranging from mega retail chains to individual grocers.

Due to their large market reach and resource availability, large growers benefit from economies of scale. They can also avail themselves of the latest, high-tech tools and techniques. We find that it is common for large growers to be vertically integrated in that they also own the processing plant and the distribution center. The small growers, on the other hand, are normally well connected to the local market, but not having sufficient resources at their disposal they do not afford high-tech equipments, nor do they own processing plants or DCs. The medium size growers fall somewhere in between in terms of their capabilities and performance potential.

The independent processing plants usually serve a large number of small to medium growers, and it is common for them to also own DCs. The grower-owned DCs are typically located close to farms owned by the growers and not the customers. Processor-owned DCs are usually located in the geographic center of the region from where they receive the fresh produce supply. Large retail chains also own DCs but they rarely undertake processing and simply receive the cleaned and packaged produce and are located centrally for economical distribution of procured products to retail outlets.

Figure 4: A Manufacturing Perspective on a FP-SC Network

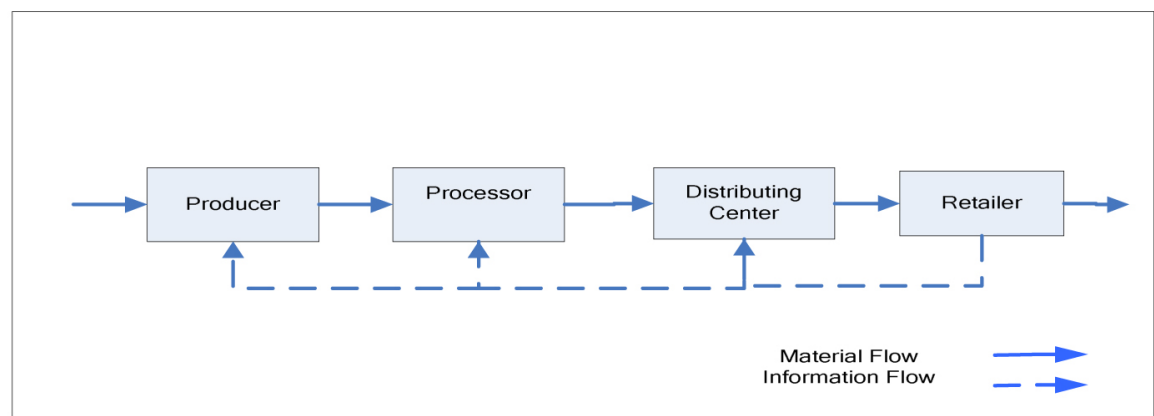

Given the nature and relationships of various parties in the fresh produce supply chain, its specific topological structure can be analyzed using the concept - networks of critical infrastructure (Lewis 2006). This concept is routinely used in analyzing the potential for systemic failure in the electric distribution networks and other utility industries. The networks of critical infrastructure are divided in two classes based on their topological structures: scale-free networks and small-world networks.

As defined by Barabasi (2003), the term "scale-free" does not refer to the size or the expanse of the network, but it relates to the degree of a node, $k$, specified as the number of edges connected to that node, that obeys a power law and has no variance (scale). A 
simple test can be used to verify if a network is scalefree (Lewis 2006). Figure 5(A) illustrates a simplified instance of this network. These networks contain very few nodes with high degrees, usually referred to as the hubs. As seen in Figure 5(A) the hubs $\boldsymbol{b}$ and $d$, respectively, are characterized by 9 and 5 degrees. Hubs play critically important role in determining the vulnerability to contamination of the fresh produce supply chain that is scale-free. For example, if a product contaminated with bacteria is present at the hubs $\boldsymbol{b}$ or $\boldsymbol{d}$, the contamination can spread rather easily throughout the entire supply chain. But with the same token, if hubs are properly designed and protected so that the contamination does not spread because of contact between different batches of fresh produce, the supply chain's vulnerability to contamination can be minimized.

Figure 5: Topological Structures: Scale-free and Small-world Networks

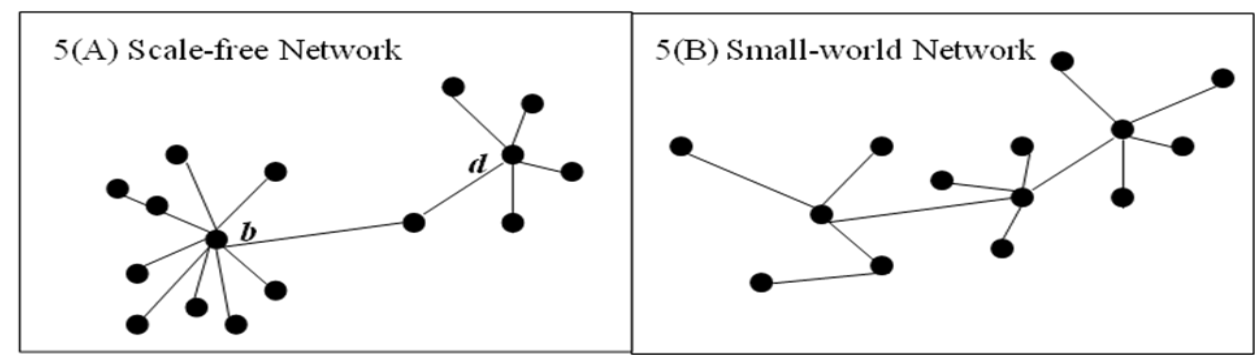

In a fresh produce supply chain, a contamination can spread with certain probability which can be modeled as the fault cascading through the network. Furthermore, if the spread rate is below a certain threshold, contamination is eradicated and is not propagated in a network. Unfortunately, in scale-free network hubs, the threshold of spread-rate is zero (Lewis 2006), and hence simply reducing the spread rate does not prevent contamination. Protecting the hub can reduce but not completely eliminate the risk of cascading contamination.

The other topological structure, depicted in Figure 5(B), is called a small-world network (Watts 1999). This configuration has clusters of connected subnetworks such that any node can be reached from any other node within a few steps. In a small-world network, hubs do exist, but they are well distributed and their degrees are much smaller than that of hubs in scale-free networks. In case of small-world networks, protecting certain nodes may reduce the risk only marginally. The cost of protection here can be higher, since there exist many inter-connected nodes within a cluster. But, on the other hand, if in case not all clusters are connected with each other, contamination has the potential to remain localized.

In general, the topological structures can be controlled to some extent with changes in the ownership of DCs. However, it should be noted that quickly modifying such design elements of the fresh produce SCN is extremely difficult since the SCN typically evolves through a series of strategic and operational decisions made by multiple parties over time. Therefore, this contributing factor is not really controllable in the short term. But developing an understanding of the current topological structure of SCN is critically important for managing vulnerability through protecting selected nodes against the spread of contamination.

\subsection{Exposure to contamination}

The Center for Disease Control and Prevention estimates that millions of consumers become sick every year due to exposure to contamination in our food supply. The interviews conducted by the researchers during the Spinach case study also revealed that prior to the processing the fresh produce invariably exhibits an exposure to contamination. Because exposure to contamination is a serious vulnerability of FP-SC, it requires closer scrutiny. A product's exposure to contaminants, such as organic compounds, bacteria, pests and pesticides, usually comes about through natural causes and phenomenon. But they can also be the result of sabotage. Furthermore, today's fresh produce supply chains are becoming increasingly vulnerable to large-scale contamination due to their highly industrialized and centralized nature. 
If producers understand effective ways for minimizing the exposure to contamination, the FP-SC's vulnerability to disruption by contamination can mitigated. Exposure to contamination is best controlled through regulating farm environments and processing plants, monitoring and maintaining correct temperatures in warehouses and in transportation, and tracking the product in its journey from the source to the destination. More specifically, risk of natural contaminant exposure can be controlled through proper storage and preservatives, while contamination from proximity to harmful bacteria can be managed with precautionary barriers. Deliberate toxin contamination can only be managed with a secure infrastructure and strictly-followed sanitation protocols. The Hazard Analysis and Critical Control Point System, HACCPS-developed in response to E. coli contamination of beef (Pollan 2006)-has been proven effective in the meat industry.

In summary, it should be noted that exposure to contamination is a controllable contributing factor.

\subsection{Traceability of the Product}

SCN design can be further analyzed in terms of product traceability. Inability to trace the source of contaminated product not only creates a marketing nightmare for growers, but more importantly it can also be fatal to consumers. Hence, although not committing resources to tracking may have day-today monetary benefits, there are dire consequences if this contributing factor is ignored during a contamination event.

Traceability can protect SCNs from disruption in several ways. First, if the source of a contamination is traced quickly, corrective actions can be taken and wide-spread product contamination and the resulting damage can be minimized. Examples of corrective actions include quarantining the product originating from the source and issuing specific remedial solutions. Second, by tracing the contamination's source, information regarding the unaffected nodes can be used to mitigate supply chain disruption and protect customers and producers. Third, a swift identification of contamination source can lead to improved communication to customers and better damage control.

Improving traceability of products in the supply chain is typically accomplished by using identification technologies such as bar codes or radio frequency identification (RFID). For example, using standardized bar code identification on a package of fresh produce makes it possible to trace not only the farm where the product was picked but also the specific batch and the day when the product was washed and packaged in the processing plant and the transportation route it subsequently followed.

Finally, we wish to point out that while traceability is an important contributing factor, it is also a powerful managerial tool which, if used properly, can help to manage supply chain disruptions.

\subsection{Communication}

Improved communication and the resulting improvement in the flow of information are important to the success of any supply chain. But well-managed communication is of particular importance during a supply chain disruption. For example, assuming that the location and the source of contamination are quickly determined, customers should be informed about the safety of using the products from uncontaminated sources, and thereby reducing the magnitude of disruption in the supply chain. As indicated by the literature (Harland and Knight 2001, Harland et al. 2004, Yee et al. 2005, Wilson and Clarke 1998) and our own observations in the Spinach case study, the role of communication is seen as a contributing factor to the vulnerability for disruption from contamination in the fresh produce supply chain. A company's ability to communicate relevant, real-time information assures consumer of product's safety and afford timely problem identification (Wilson and Clarke 1998).

The lack of information dissemination can exacerbate the damaging impact of a disruption. Ideally, producers should educate customers before a disruption occurs, providing directives on storage, transportation, and consumption of perishable and essential products. For example, after the E. coli contamination of beef in the US, an aggressive campaign urging customers to heat beef to a certain temperature prior to its consumption was undertaken. It has proven to greatly reduce the consumer risk. This event illustrates that in the fresh produce industry "the farmers should understand what customers want to know and provide accurate and reliable information" (Yee et al. 2005). Finally, it is evident from the above discussion that communication-both before and after a disruption-is a contributing factor that also serves as a controllable management lever.

\subsection{Proposed Conceptual Model}


As discussed earlier, there exist five contributing factors that collectively determine a fresh produce supply chain's vulnerability to disruption from contamination. These factors are product type, topolog- ical structure of the FP-SC, exposure to contamination, product traceability, and communication. The proposed conceptual model (Figure 6) depicts these factors and their impact on vulnerability to disruption in the form of an influence diagram.

Figure 6: Conceptual Model

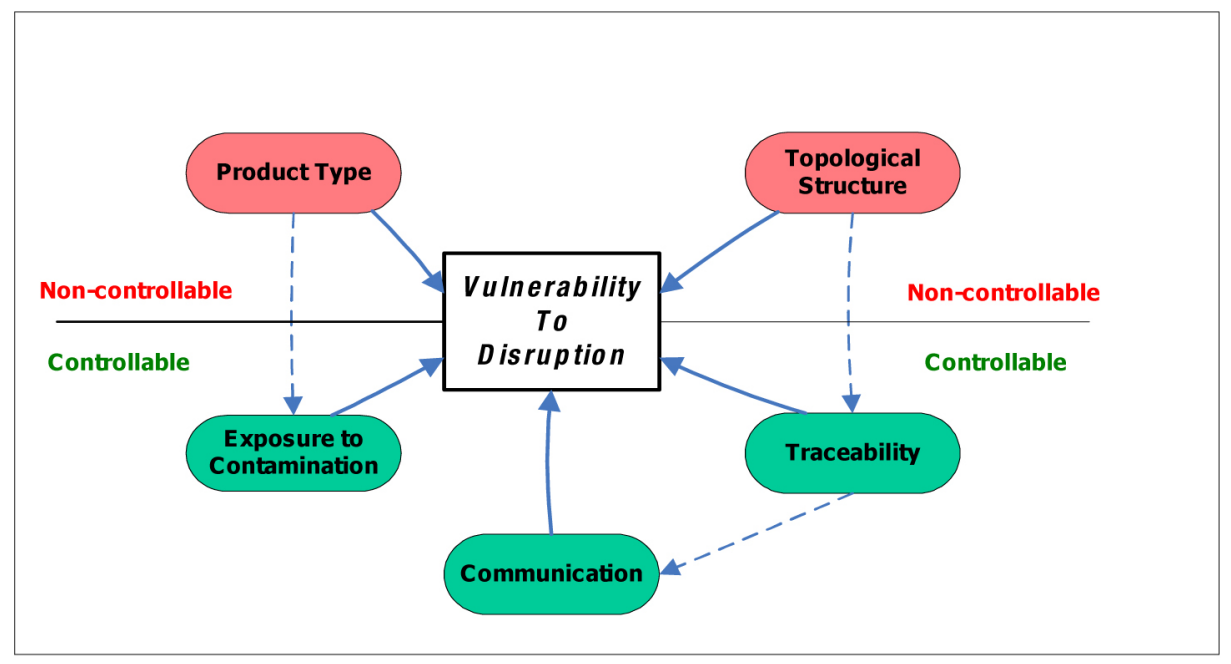

The figure also divides these five factors in two groups: those that can be controlled by the management and others that are non-controllable. For example, traceability, communication, and exposure to contamination are seen as controllable factors. Thus, these three controllable factors can be used as levers that the managers can use to minimize vulnerability to disruption from contamination in a FP-SC. The other two contributing factors - product type and topological structure - are non-controllable factors, at least in the short term. But these contributing factors should also be analyzed so that suitable actions, such as protecting hubs from contamination, can be taken.

In addition, the arrows shown with dashed lines in Figure 6 illustrate the relationships between the factors. For example, as seen in the figure, communication is a management-controllable contributing factor. But communication is also a factor that depends on the product traceability. This means that for communication to serve as an effective tool in minimizing the vulnerability to disruption from contamination, it is important that traceability of the product be improved. Interestingly, both traceability and exposure to contamination are controllable factors which respectively depend on topological structure and product type. To the extent the latter two are uncontrollable factors, there is a limit on the extent to which traceability and exposure to contamination can be improved. We illustrate the proposed conceptual framework in the next section through its application to the case study of a fresh produce supply chain.

\section{A FRESH PRODUCE SUPPLY CHAIN CASE STUDY}

In September 2006, when 26 people nationwide were diagnosed with E. coli from eating contaminated spinach, it took investigators several weeks to conclude their investigation of the farms in the Salinas Valley and the nearby areas (Figure 2). The lack of information in the interim regarding the source of contamination resulted in a ban against all spinach originating from the region. At the end of the investigation, no farm from Monterey County was found to be contaminated. In fact, a spinach packaging company from the San Benito County (Figure 2) was found culpable. Before delving into the analysis of this incident and its aftermath, it would be useful to establish a basic understanding of the Salinas Valley spinach industry.

Most large-scale growers in the industry are family-owned and are run efficiently with the latest operational techniques - including continuous process improvement and database management. High-tech 
tools, such as lasers to level farms for equal water distribution and GPS-enabled farm equipment are also standard operating practices. The growers are regulation compliant and are diligent in ensuring product traceability. Furthermore, most growers are members of the California Green Products Handlers Marketing Agreement (LGMA) and have self-imposed measures to protect their FP-SC from contamination vulnerabilities. The Salinas Valley spinach industry is examined below from the perspective of each contributing factors defined in the conceptual framework.

\subsection{Product Type}

Most growers are large-scale companies; but there exist scattered medium-scale, and numerous smallscale growers in the region. Their product is offered in both "wash-before-eat" and "ready-to-eat" forms with some growers specializing while others producing various product forms. Following the definitions offered earlier, wash-before-eat spinach is characterized as a perishable and essential product, while ready-to-eat forms are classified as perishable and somewhat-essential or non-essential products.

\subsection{Topological Structure}

The DCs are owned by growers or retailers. Growerowned DCs are usually located close to farms while retailer-owned DCs are close to the end-users. Exposure to contamination may rise with longer transit-times and if transit temperature is not properly controlled. In many cases, small establishments sell directly to retailers.

Figure 7: SCN of Large Growers for Essential Products

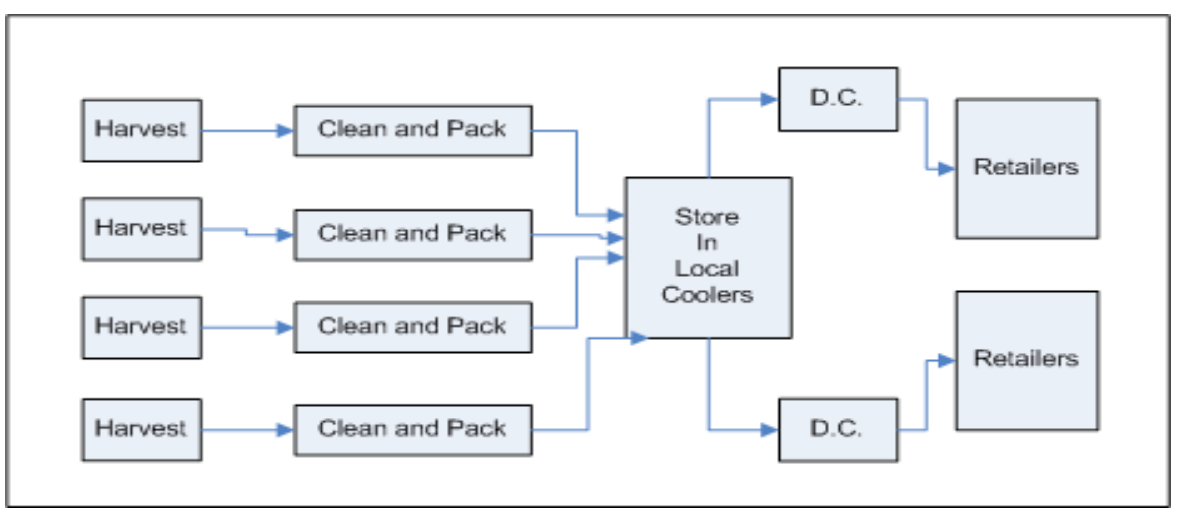

The SCNs of large growers for essential products and somewhat-essential or non-essential products are illustrated in Figure 7 and Figure 8 respectively. Advantages offered by large-scale grower, particularly the economies of scale, make their SCNs more complex and their design can be compared to that of scale-free networks (Figure 5). Within the supply chain for essential products, the "Store in Local Coolers" node is the hub, whereas in the supply chain for somewhat-essential or non-essential products, the "Clean and Pack" node is the hub.

Figure 8: SCN of Large Growers for Somewhat-essential or Non-essential Products

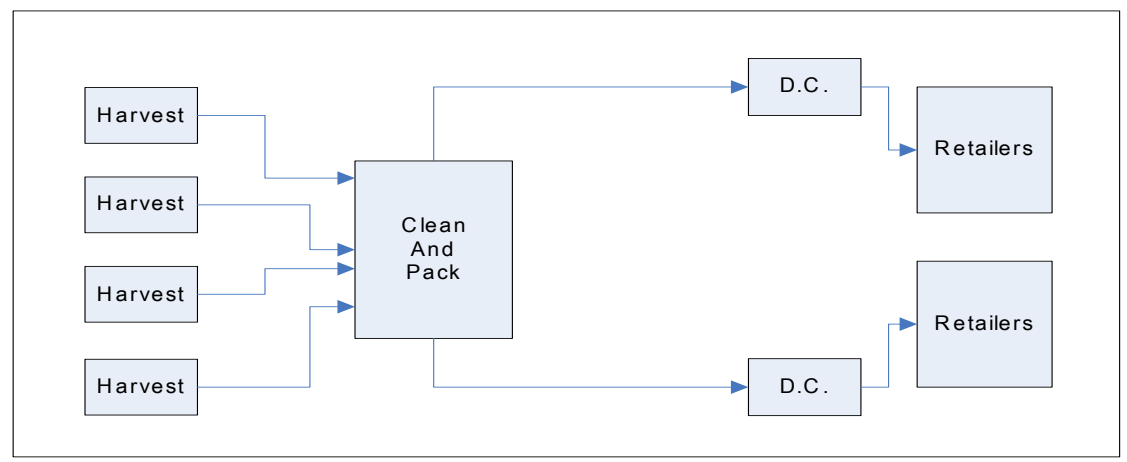


Figure 9: SCN of Small Growers for All Products

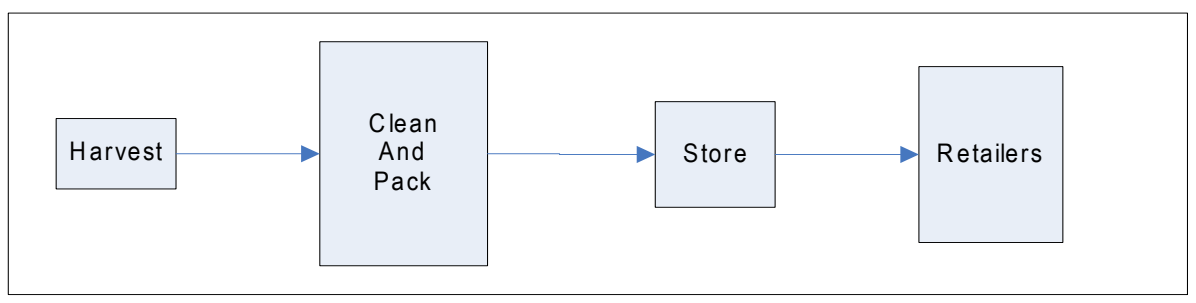

Figure 9 illustrates the SCN for small growers, which in conjunction with their end-users, can be thought of as small-world networks (Figure 5). Unlike largescale growers, these establishments are scattered throughout the region with large, sparse networks. Lack of distribution or packing centers eliminates hub, making it harder to fully protect this SCN factor against vulnerability to disruption.

\subsection{Exposure to contamination}

Topological structure of large-scale growers SCN is closely linked to exposure to contamination since the distribution hubs are locations of increased risk. As a result, protecting these hubs is critical. Producers and distributors are managing exposure to contamination by following LGMA regulations, placing barriers between farms and surrounding areas to control pollutants, and conducting compliance spot-checks for quality control. Regulations are self-imposed, and for the most part, the barriers are able to trap pests and prevent deer from entering the farms.

For large- and small-scale growers both, contamination can arise from product handling. Some fresh produce - e.g., lettuce, strawberries and artichokes - are hand-picked. In contrast, spinach is generally harvested using complete automation, which increases potential for exposure to contamination due to occasional presence of pests and pesticides within the harvested product. In such cases the packaged product results in further contamination as it degrades over time during transportation.

\subsection{Traceability}

Among the most large-scale growers we interviewed, the record of traceability was excellent. Cartons of fresh produce are bar-coded to identify origin, picker, and harvesting time. For example, Driscoll's growers, Reiter Berry Farms, keep meticulous documentation of all the inputs in any box of berries including: seed used; soil; fertilizer; originating sector of the farm; picker; and picking time. This kind of traceability is of significant value against vulnerability to disruption in the SCN. Most largescale grower SCNs were efficient and remained vigilent in tracking the product.

In contrast, since small-scale growers sell directly to retailers, there are no intermediate nodes resulting in good traceability. In addition, the lack of documentation also made product tracking a challenging task. However, since the network is not completely connected a contamination can be potentially localized and thus other growers are protected. Since the incident of spinach contamination, traceability has been improved further with all producers maintaining more meticulous input documentation.

\subsection{Communication}

The role of communication has been critical in community education and for controlling damage to the industry's reputation from past contaminations. Most growers, packers and agriculture-related businesses in Monterey County have been actively involved in educating the community about contamination sources, appropriate precautions, and preventative measures that can be taken by both growers and consumers.

\subsection{Summary and Discussion}

The case study identified a number of important points regarding large-scale and small-scale growers. Large-scale grower SCNs resemble scale-free networks with clearly defined hubs. A hub disruption can mean major monetary or human loss consequences. If the hubs are properly protected, the SCN's vulnerability to disruption can be reduced. In contrast, small-scale grower SCNs are usually local and comparable to small-world networks, which clearly contain clusters and are sparse in nature. However, unlike small-world networks (where all nodes are connected), in small-scale grower SCNs the nodes are not necessarily all interconnected. This characteristic can help isolate a contamination event. Moreover, since there are no prominent hubs, vulnerability to contamination and, hence, disruption is also reduced. 
The three controllable contributing factors - exposure to contamination, traceability, and communication - were utilized by the industry to reduce SCN disruption. The exposure to contamination and traceability were actively monitored by both largescale and small-scale growers. Limited resources for small-scale growers meant that the role of communication was pursued less frequently. Medium-scale growers, on the other hand, were found to be utilizing some of the controllable contributing factors as available resources permitted.

At the time of this research, according to estimates from Stephen Griffin of Misonero Vegetables and ABC Labs in Salinas, California, the probability of another such episode occurring in the future has been reduced substantially due to the voluntary measures adopted by the industry. The "Good Agricultural Practices" (GAP), general principles (FAO 2009) developed by the Food and Agricultural Organization (FAO) of the United Nations, which has been in existence since 2003, and the formation of California Leafy Green Products Handler Marketing Agreement (LGMA) in 2007 to raise the bar in food safety are also partly responsible for the reduced vulnerability of fresh produce supply chain to disruption from contamination.

\section{CONCLUSION AND CONTRIBUTION}

We investigated the design and provided an understanding of five major contributing factors to vulnerability of disruption due to contamination of a fresh produce supply chain: product type; topological structure; exposure to contamination; product traceability; and communication. The conceptual framework shows the relationship between these factors and identifies which factors can be used as controllable management levers.

The primary theoretical contributions of this research are the improved understanding of the fresh produce supply chains and the development of a conceptual framework consisting of the contributing factors for the vulnerability of these supply chains to disruption from contamination. The practice related contributions of this research are managerial insight and recommended actions derived from the proposed conceptual framework.

The literature reviewed helped us ground our research in finding resolution to the key issues in the vulnerability to disruption of the FP-SC. Our analysis of the contributing factors and their categoriza- tion recommended the management of the factors. Though the literature reviewed served as a guide it also revealed the gaps in the extant research so far as how to exploit the factors to manage the vulnerabilities to disruption of the supply chain. Our research was focused on fresh produce which also extended these concepts in a relatively new area of vulnerability of the food supply chain.

Product types were defined on a continuum of perishability and essentialness, while SCN topological structure were defined and analyzed in terms Scale-free and Small-world networks. The contributing factors of product type and topological structure are primarily intrinsic and are difficult to change in the short-term. In contrast, the other contributing factors are all controllable and hence can serve as viable management levers. For example, specific nodes in SCN can be protected against exposure to contamination; traceability of the product can be improved; and responsive and timely communication can allay consumer fear, thus stabilizing demand in case of a contamination event.

The conceptual model was discussed in general and was applied against a specific instance of contamination in the fresh produce industry and analyzed. Such analysis strengthens the understanding of contributing factors. The case study described the events that followed the spinach (product type) contamination in a localized region (topological structure and design) over the course of the several-week investigation to identify the contamination source (exposure to contamination). The case further explored the SCN disruption due to inadequate product source information (traceability), and communication problems (role of communication). An inability to locate the contamination source, lack of traceability, and delayed communication exacerbated the SCN disruption and ultimately resulted in large economic cost to producers. All three of these contributing factors were controllable and measures are now in place to better protect the industry from future contamination events. An additional contribution from this research is that large-scale growers can minimize SCN vulnerabilities by protecting distribution hubs, a suggestion that is likely to be cost-prohibitive for smallscale growers. For all growers, increased communication should be a prominent strategy for damage control; only achievable with effective traceability.

\section{FUTURE RESEARCH}

The mapping of SCN, discussion of the design of this network and the analysis of the contributing factors in the fresh produce commodity can now lead the 
way for further research on the topic. Limitations of the current research can also provide direction for future research. It is likely that there exist other underlying issues related to each of the contributing factors. For example, exposure to contamination is a vast and difficult technical issue in the fresh produce supply chains with a significant potential for further investigation. Additionally, the research could also be extended by investigating other operational contributing factors, such as demand patterns, inventory levels, ordering cycles, and operational processes. Efficient and responsive processes to satisfy demand are not necessarily mutually exclusive, but each process type requires distinct strategy within SCN design requiring specific study. This possibility could be explored by utilizing a survey instrument. Despite primarily focusing on the 2006 Salinas Valley spinach contamination, the findings of the current research can be expanded to include supply chain vulnerabilities of other perishable and essential products.

\section{REFERENCES}

Ahuja, R. K., Magnanti, T. L., and Orlin, J. B. (1993). Network Flows Theory, Algorithms, and Applications. Prentice Hall, Englewood Cliffs, New Jersey.

Asbjornslett, B. E. (2008). Assessing the Vulnerability of Supply Chains, In Supply Chain Risk: A Handbook of Assessment, Management, and Performance, (G. A. Zsidisin and B. Ritchie eds.), New York: Springer, 2008

Barabasi, A. L. (2003). Linked: How Everything Is Connected To Everything Else and What It Means for Business, Science, and Everyday Life. PLUME Cambridge Center, Cambridge, Massachusetts.

Chopra, S. and Meindl, P. (2004). Supply Chain Management Strategy, Planning, and Operations (Second Edition). Pearson/Prentice Hall, Upper Saddle River, New Jersey.

Dani, S. (2008). Predicting and Managing Supply Chain Risks, In Supply Chain Risk: A Handbook of Assessment, Management, and Performance, (G. A. Zsidisin and B. Ritchie eds.), New York: Springer, 2008.

Dyer, J. and Nobeoka, K. (2000). Creating and Managing High Performance Knowledge, Sharing Network: The Toyota Case, Strategic Management Journal, 21, 343-367

Food and Agricultural Organization (FAO) (2009). http:/ / www. fao.org/prods/GAP/home/principles_en.htm,Accessed on March 19, 2009.

Fine, C. H. (1998). Clockspeed. Perseus Books, Reading, Massachusetts.

Fisher, M. L. (1997). What is the Right Supply Chain for Your Product? Harvard Business Review, 75(2), 105-116.
Folinas, D., Manikas, I. and Manos, B. (2006). Traceability Data Management for Food Chains, British Food Journal, 108(8), 622-623

Golan, E. B., Krissoff, F., Kuchler, L., Calvin, K. N., and Price, G. (2004). Traceability in the U. S. Food Supply: Economic Theory and Industry Studies. Economic Research Service, U. S. Department of Agriculture, Agricultural Economic Report No. 830.

Handfield, R. B., Blackhurst, J., Elkins, D., and Craighead C. W. (2008). A Framework for Reducing the Impact of Disruptions to the Supply Chain: Observations from Multiple Executives, In Supply Chain Risk Management, (R. B. Handfield and K. McCormack eds.), New York: Auerbach Publications, 2008.

Harland, C.M., Lamming, R.C., and Counsins, P.D. (1999). Developing the concept of supply strategy, International Journal of Operation and Production Management, 21(4), 476-489

Harland, C.M. and Knight, L. A. (2001). Supply Network Strategy: Role and Competence Requirements, International Journal of Operation and Production Management, 19(7), 650-673

Harland, C.M., Zheng, J., Johnsen, T., and Lamming, R. (2004) A Conceptual Model for Researching Creation and Operation of Supply Networks, British Journal of Management, 15, 1-21

Hendricks, K. B. and Singhal, V. R., "Managing Disruptions in Contemporary Supply Chains," Dynamic Supply Chain Alignment, edited by J. Gattorna, Aldershot: Gower, pp. 8596, 2009.

Khan O., Christopher, M., and Burnes, B. (2008). The Role of Product Design in Global Supply Chain Risk Management, In Supply Chain Risk: A Handbook of Assessment, Management, and Performance, (G. A. Zsidisin and B. Ritchie eds.), New York: Springer, 2008.

Lamming, R., Johnsen, T., Zheng, J., and Harland, C. M. (2000). An initial classification of supply networks, International Journal of Operations and Production Management, 20(6), 675-691.

Lewis, T. G. (2006). Critical Infrastructure Protection in Homeland Security: Defending a Networked Nation. Wiley-Interscience, Hoboken, NJ.

Maloni, M. J. and Brown, M. E. (2006). Corporate Social Responsibility in the Supply Chain: An Application in the Food Industry, Journal of Business Ethics, 68(1), 35-52.

Manning, L., Baines, R. N., \& Chadd, S. A. (2006). Food Safety Management in Broiler Meat Production, British Food Journal, 108(8), 606-621

Meredith, J. (1993) Theory Building through Conceptual Methods, International Journal of Production $\mathcal{E}$ Operations Management, 13(5), 3-11

Morgan, N. A., Anderson, E. W., and Mittal, V. (2005). Understanding Firm's Customer Satisfaction Information Usage, Journal of Marketing, 69(3), 131-151

Mullal, A. (2008). Risk Management System - A Conceptual Model, In Supply Chain Risk: A Handbook of Assessment, Management, and Performance, (G. A. Zsidisin and B. Ritchie eds.), New York: Springer, 2008. 
Peck, H. (2005). Drivers of supply chain vulnerability: an integrated framework, International Journal of Physical Distribution and Logistics Management, 35(4), 210-232

Pollan, M. (2006). The Vegetable-Industrial Complex. The New York Times Magazine. October 15, 2006, 17.

Roth, A. V., Tsay, A. A., Pullman, M. E., and Gray, J. V. (2008). Unraveling the Food Supply Chain: Strategic Insights from China and the 2007 Recalls, Journal of Supply Chain Management, 44, 22-39

Smith, C. (2000). The Characteristics of the Food Industry Supplier of the Future. Available at http:/ /www.ici.com/main/ cms/cmRender.asp?i=1463 (Downloaded 5/13/08)

Svensson, G. (2000). A Conceptual Framework for the Analysis of Vulnerability in Supply Chains. International Journal of Physical Distribution and Logistics Management, 30(9), 731-749.

Uzzi, B. (1997). Social Structure and Competition in Interfirm Networks: The Paradox of Embeddedness, Administrative Science Quarterly, 42, 35-67

Van Donk, D. P. and Van Dam, P. (1996). Structuring Complexity in Scheduling: A Study in a Food Processing Industry, International Journal of Operations and Production Management, 16(5), 54-63
Wagner, S. M. and Bode, C. (2008). Dominant Risks and Risk Management Practices in Supply Chains, In Supply Chain Risk: A Handbook of Assessment, Management, and Performance, (G. A. Zsidisin and B. Ritchie eds.), New York: Springer, 2008.

Watts, D. (1999). Networks, Dynamics, and Small-World Phenomenon. American Journal of Sociology, 105(2), 493-527.

Webster's (1980). Webster's New World Dictionary, Publisher, City, State.

Wein, L. M. (2005). Got Toxic Milk? The New York Times. May 30, 2005, 15.

Westbrook, R. (1995). Action Research: A New Paradigm for Research in Production and Operations Management, International Journal of Operations and Production Management, 15(12), 6-20

Wilson, T. P. and Clarke, W. R. (1998). Food Safety and Traceability in the Agricultural Supply Chain: Using the Internet to Deliver Traceability, Supply Chain Management, 3(3), 127-133

Yee, W. M. S., Yeung, R. M. W., and Morris, J. (2005). Food Safety: Building Consumer Trust in Livestock Farmers for Potential Purchase Behavior, British Food Journal, 107(11), 841-854

Yin, R. K. (2003). Case Study Research: Design and Methods (Third Edition). Sage Publications, Thousand Oaks, California.

\section{APPENDIX}

\section{Table 1: Data Collection}

\begin{tabular}{|c|c|c|c|c|c|c|c|}
\hline \multirow[b]{2}{*}{ Sector } & \multirow[b]{2}{*}{ Role } & \multicolumn{4}{|c|}{ Data Collection } & \multirow{2}{*}{$\begin{array}{c}\text { Geographical } \\
\text { Site }\end{array}$} & \multirow{2}{*}{$\begin{array}{c}\text { Resulting } \\
\text { Contributing } \\
\text { Factor }\end{array}$} \\
\hline & & Presentation & Discussion & Interview & $\begin{array}{l}\text { Field- } \\
\text { Visit }\end{array}$ & & \\
\hline $\begin{array}{l}\text { Agricultural } \\
\text { Issues }\end{array}$ & $\begin{array}{l}\text { Public } \\
\text { Official }\end{array}$ & $\square$ & & & & Monterey & $\begin{array}{c}\text { Role of } \\
\text { Communication } \\
(\mathrm{RoC})\end{array}$ \\
\hline $\begin{array}{l}\text { Production } \\
\text { Distribution }\end{array}$ & $\begin{array}{l}\text { Executive } \\
\text { Vice } \\
\text { President }\end{array}$ & $\square$ & $\square$ & $\square$ & $\square$ & Salinas & $\begin{array}{c}\text { Topological } \\
\text { Structure (TS) }\end{array}$ \\
\hline Processing & President & $\square$ & $\square$ & $\square$ & $\square$ & Salinas & $\begin{array}{l}\text { TS, Contamination } \\
\text { (C), Traceability (T) }\end{array}$ \\
\hline $\begin{array}{l}\text { Agricultural } \\
\text { Issues }\end{array}$ & $\begin{array}{l}\text { Public } \\
\text { Official }\end{array}$ & $\square$ & & $\square$ & & Salinas & RoC, C \\
\hline $\begin{array}{l}\text { Resources } \\
\text { (Land) }\end{array}$ & $\begin{array}{l}\text { Assistant } \\
\text { Director }\end{array}$ & $\square$ & & & & Salinas & $\mathrm{C}, \mathrm{T}$ \\
\hline $\begin{array}{l}\text { Resources } \\
\text { (Land) }\end{array}$ & $\begin{array}{l}\text { Service } \\
\text { Planner }\end{array}$ & $\square$ & & & & Salinas & $\mathrm{C}, \mathrm{T}$ \\
\hline
\end{tabular}




\begin{tabular}{|c|c|c|c|c|c|c|c|}
\hline $\begin{array}{l}\text { Resources } \\
\text { (Air) }\end{array}$ & $\begin{array}{l}\text { Air Pollution } \\
\text { Controller }\end{array}$ & $\square$ & $\square$ & & & Monterey & $\mathrm{C}, \mathrm{T}$ \\
\hline $\begin{array}{l}\text { Resources } \\
\text { (Air) }\end{array}$ & $\begin{array}{l}\text { Air Pollution } \\
\text { Controller }\end{array}$ & $\square$ & & & & Monterey & $\mathrm{C}, \mathrm{T}$ \\
\hline $\begin{array}{l}\text { Resources } \\
\text { (Air) }\end{array}$ & $\begin{array}{l}\text { Air Pollution } \\
\text { Controller }\end{array}$ & & & $\square$ & & Monterey & $\mathrm{C}, \mathrm{T}$ \\
\hline $\begin{array}{l}\text { Resources } \\
\text { (Water) } \\
\text { Production }\end{array}$ & $\begin{array}{l}\text { Owner } \\
\text { Farmer }\end{array}$ & & $\square$ & & $\square$ & Castroville & All \\
\hline $\begin{array}{l}\text { Resources } \\
\text { (Water) }\end{array}$ & Innovator & & & $\square$ & $\square$ & Salinas & $\mathrm{C}$ \\
\hline $\begin{array}{l}\text { Resources } \\
\text { (Water) }\end{array}$ & $\begin{array}{c}\text { General } \\
\text { Manager }\end{array}$ & $\square$ & $\square$ & $\square$ & & Monterey & $\mathrm{C}$ \\
\hline $\begin{array}{l}\text { Resources } \\
\text { (Water) }\end{array}$ & $\begin{array}{l}\text { Assistant } \\
\text { General } \\
\text { Manager }\end{array}$ & $\square$ & & & & Monterey & $\mathrm{C}$ \\
\hline $\begin{array}{l}\text { Resources } \\
\text { (Water) }\end{array}$ & $\begin{array}{l}\text { Public } \\
\text { Official }\end{array}$ & $\square$ & $\square$ & & & Salinas & $\mathrm{C}$ \\
\hline $\begin{array}{l}\text { Resources } \\
\text { (Water) }\end{array}$ & $\begin{array}{l}\text { Public } \\
\text { Official }\end{array}$ & $\square$ & & $\square$ & & Salinas & $\mathrm{C}$ \\
\hline $\begin{array}{l}\text { Resources } \\
\text { (Water) }\end{array}$ & Coordinator & $\square$ & $\square$ & & & Spreckles & $\mathrm{C}$ \\
\hline Production & Rancher & & $\square$ & $\square$ & $\square$ & San Lucas & TS, C, T \\
\hline $\begin{array}{l}\text { Production } \\
\text { Processing } \\
\text { Distribution }\end{array}$ & Viticulturist & $\square$ & & $\square$ & $\square$ & San Lucas & All \\
\hline $\begin{array}{l}\text { Research and } \\
\text { Development }\end{array}$ & Academic & $\square$ & & & & Salinas & $\mathrm{C}, \mathrm{T}$ \\
\hline $\begin{array}{l}\text { Research and } \\
\text { Development }\end{array}$ & Enologist & & & $\square$ & $\square$ & Monterey & $\mathrm{C}, \mathrm{T}$ \\
\hline $\begin{array}{l}\text { Production } \\
\text { Distribution }\end{array}$ & Horticulturist & & $\square$ & & $\square$ & King City & TS, RoC \\
\hline
\end{tabular}




\begin{tabular}{|c|c|c|c|c|c|c|c|}
\hline $\begin{array}{l}\text { Research and } \\
\text { Development } \\
\text { Production } \\
\text { Distribution }\end{array}$ & Farmer & & $\square$ & $\square$ & $\square$ & King City & All \\
\hline Production & Farmer & & $\square$ & & $\square$ & Salinas & All \\
\hline Distribution & $\begin{array}{l}\text { Operations } \\
\text { Manager }\end{array}$ & & $\square$ & & $\square$ & Salinas & All \\
\hline $\begin{array}{l}\text { Research and } \\
\text { Development } \\
\text { Distribution }\end{array}$ & Manager & & $\square$ & $\square$ & $\square$ & Watsonville & All \\
\hline $\begin{array}{l}\text { Production } \\
\text { Distribution }\end{array}$ & President & $\square$ & $\square$ & & $\square$ & Moss Landing & C, TS, T \\
\hline $\begin{array}{l}\text { Production } \\
\text { Distribution }\end{array}$ & Farmer & & $\square$ & $\square$ & $\square$ & Watsonville & C, TS, T \\
\hline $\begin{array}{l}\text { Production } \\
\text { Processing } \\
\text { Distribution }\end{array}$ & $\begin{array}{l}\text { Owner } \\
\text { President }\end{array}$ & $\square$ & $\square$ & & $\square$ & Castroville & TS \\
\hline Processing & $\begin{array}{c}\text { Vice } \\
\text { President } \\
\text { Quality }\end{array}$ & $\square$ & $\square$ & $\square$ & $\square$ & Salinas & $\mathrm{C}, \mathrm{TS}, \mathrm{T}$ \\
\hline $\begin{array}{l}\text { Research and } \\
\text { Development } \\
\text { Food Safety }\end{array}$ & $\begin{array}{l}\text { Founder } \\
\text { President }\end{array}$ & $\square$ & $\square$ & & $\square$ & Salinas & $\mathrm{C}, \mathrm{T}, \mathrm{RoC}$ \\
\hline $\begin{array}{c}\text { Organic } \\
\text { Production } \\
\text { Distribution }\end{array}$ & $\begin{array}{c}\text { Export and } \\
\text { Operations } \\
\text { Manager }\end{array}$ & $\square$ & & $\square$ & $\square$ & Salinas & TS, RoC \\
\hline Processing & $\begin{array}{l}\text { Owner } \\
\text { President }\end{array}$ & & $\square$ & & $\square$ & Salinas & All \\
\hline $\begin{array}{l}\text { Marketing } \\
\text { Legal }\end{array}$ & $\begin{array}{l}\text { Owner } \\
\text { President }\end{array}$ & $\square$ & $\square$ & & & Salinas & $\mathrm{T}$ \\
\hline $\begin{array}{l}\text { Agricultural } \\
\text { Issues }\end{array}$ & Consultant & $\square$ & & $\square$ & & Salinas & All \\
\hline Technology & Farmer & $\square$ & & & & Salinas & $\mathrm{C}, \mathrm{T}$ \\
\hline Technology & Engineer & $\square$ & & & & Salinas & $\mathrm{C}, \mathrm{T}$ \\
\hline
\end{tabular}




\begin{tabular}{|c|c|c|c|c|c|c|c|}
\hline $\begin{array}{c}\text { Agricultural } \\
\text { Issues }\end{array}$ & $\begin{array}{c}\text { Public } \\
\text { Official }\end{array}$ & $\square$ & & & & Salinas & C, T \\
\hline $\begin{array}{c}\text { Research and } \\
\text { Development }\end{array}$ & Researcher & $\square$ & & & & Salinas & C, T \\
\hline $\begin{array}{c}\text { Agricultural } \\
\text { Issues }\end{array}$ & President & $\square$ & $\square$ & $\square$ & & Salinas & All \\
\hline $\begin{array}{c}\text { Agricultural } \\
\text { Issues }\end{array}$ & $\begin{array}{c}\text { Executive } \\
\text { Director }\end{array}$ & $\square$ & $\square$ & & & Salinas & TS, RoC \\
\hline
\end{tabular}

\section{AUTHOR'S BIOGRAPHY}

Dr. Aruna Apte is an Assistant Professor in the Department of Operations and Logistics Management, Graduate School of Business and Public Policy, at the Naval Postgraduate School, Monterey, California. She received her PhD in Operations Research from the School of Engineering at the Southern Methodist University in Dallas, Texas. Before NPS she worked as a consultant at MCI and taught at the Cox School of Business, Southern Methodist University.

Her research interests are in the areas of developing mathematical models and algorithms for complex, realworld operational problems using techniques of optimization. It is important to her that her research is directly applicable to practical problems and has significant value-adding potential. Currently she is working in the areas humanitarian logistics and military logistics. She has several publications in peer-reviewed journals, such as Interfaces, Naval Research Logistics, Production and Operations Management. She has recently published a monograph on Humanitarian Logistics. At NPS She teaches courses in mathematical modeling and has advised over 30 students for theses and MBA reports. 